Vol. 1, No. 2, 2020

Maksym Afonin

Lviv Polytechnic National University

12, Stepan Bandery Str. Lviv, 79000, Ukraine

(C) M.Afonin, 2020

https://doi.org/10.23939/tt2020.02.033

\title{
INFLUENCE OF PUBLIC TRANSPORT ERGONOMIC FEATURES ON PASSENGER'S FUNCTIONAL STATE
}

\begin{abstract}
Summary. The article means an analysis of the passenger transport services quality issue. Researches of public transport routes ergonomic features and their influence on a passenger functional condition are provided. The analysis of such indicators as cabin occupancy rate, noise level, vibration, and acceleration was carried out. Mathematical dependences of the passenger functional condition change considering vehicles ergonomic features were constructed. Threshold values of passenger compartment microclimate, providing the stress index normative values were determined. The most valuable result of the study is a comparative assessment of each type of public transport in terms of comfort and obtaining threshold values of noise, vibration, and acceleration which are acceptable for the normal passenger's functional condition.
\end{abstract}

Key words: ergonomics of rolling stock, noise, vibration, functional state, quality of transport service.

\section{INTRODUCTION}

Worldwide, the government is fighting against the use of personal motor transport versus the public. This is because the city streets are congested, new junctions and engineering solutions require significant funds and do not guarantee the solution of the problems associated with a large number of cars on the city network. There is also a global problem of harmful emissions into the atmosphere. In such conditions, public transport comes to the fore in matters of population mobility.

To ensure the attractiveness of this mobility type, it is necessary to implement such conditions that take into account the maximum number of factors - executive staff, convenient ticket operations, passenger infrastructure development, seating and free space, the comfort of return, vehicle ergonomics, travel comfort, etc.

\section{RESEARCH STATEMENT}

In Ukraine and Lviv in particular, passenger public transport is very relevant and popular. The main task, at this moment, is to improve traffic conditions, travel comfort, traffic routes, and also to update the fleet and meet the needs of passengers by increasing the number of public transport in certain areas.

In recent years, the fleet is being renewed, more modern vehicles are being purchased, but the human factor is still not taken into account. No new results are conducted to study travel conditions and analyze passenger needs.

The study of transport service is engaged in many foreign authors [1-3] and Ukrainian scholars

[4-6]. It is also worth noting that, at present, there are a small number of regulations that define the requirements for vehicles used for the carriage of passengers [7]. The classification of methods for assessing the quality of transport services is to summarize the criteria which, to some extent, are important when choosing transportation mode. These criteria are best described by the author [8] in the form of the following scheme: 


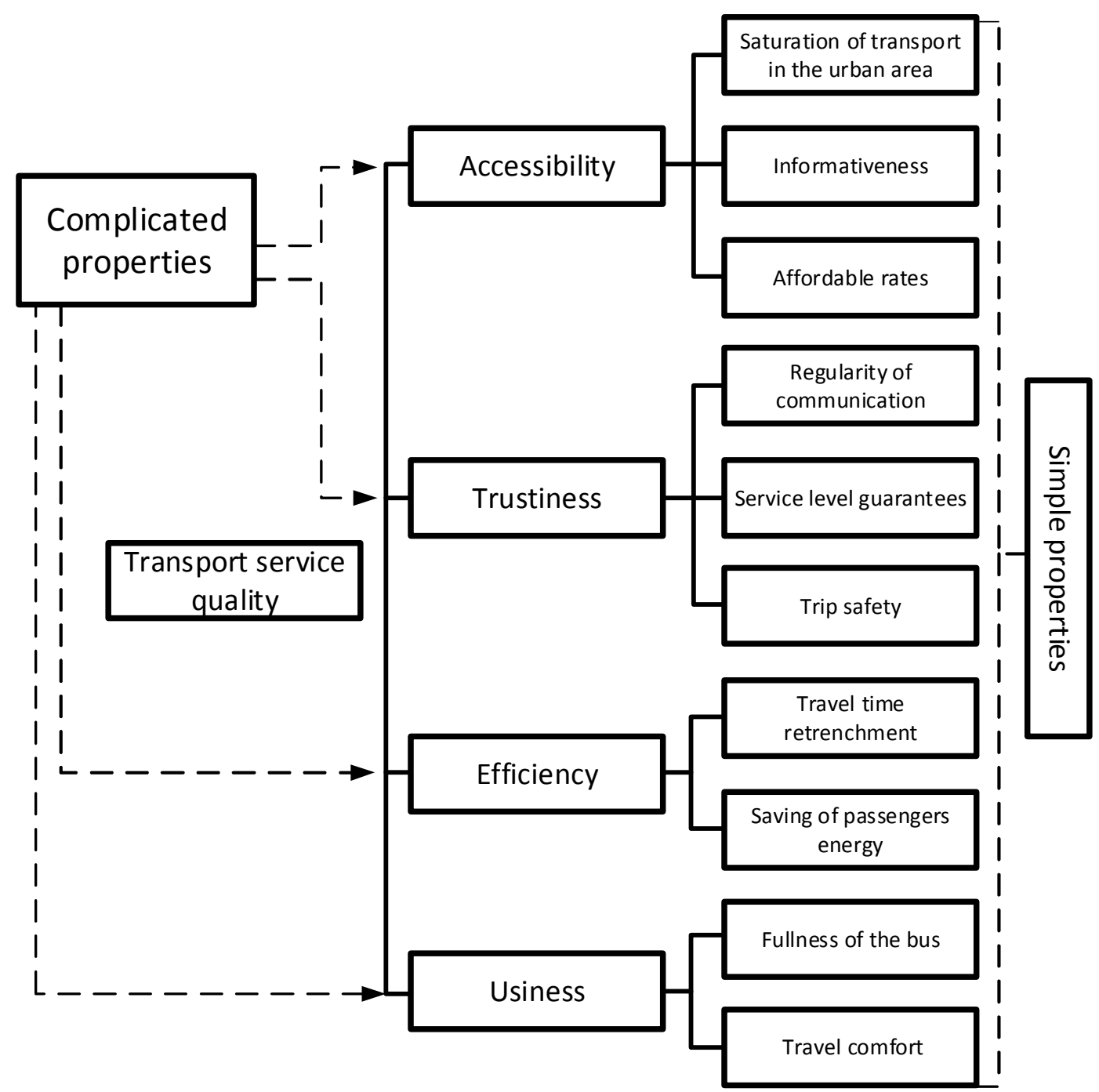

Fig. 1. The structure of the passenger service quality indicators [8]

As seen from the block diagram, the basic properties of transport that characterize the quality of transport services are divided into four major blocks. The least researched of them is usiness. The reason is in the hardness of its digitizing to provide not only quality but also a quantitative assessment.

Given all the above, the study of passengers' functional state is a topical issue today. At the outset, this study is important for the working population, as their labour depends entirely on well-being, and within a large city, where the average travel time, according to the rules [9] is about 35-45 minutes - a sufficient period to be strongly influenced by adverse factors, especially during rush hours - morning and evening. The purpose of the research is to identify patterns in the passengers' functional state (FS) indicators, depending on the public transport ergonomic features. The main objectives of the research are:

- determining factors characterizing ergonomics of vehicles and influencing on passengers` FS;

- research of passengers' FS indicators change at the use of various public transport modes;

- determination of public transport ergonomic parameters that correspond to the optimal passengers' FS.

\section{RESEARCH METHODOLOGY}

Research of changes in passenger's FS and ergonomic features of vehicles was held in Lviv. They took place on weekdays in the morning from 09:00-10:00, lunch - 13:00-14:00 and in the evening from 17:00-18:00. For this purpose, the following route directions of public transport were chosen (Fig. 2):

1. Bus routes: $\# 3 \mathrm{~A}, \# 9, \# 21$; 
2. Tram route: \#3;

3. Trolleybus route: $\# 2$.

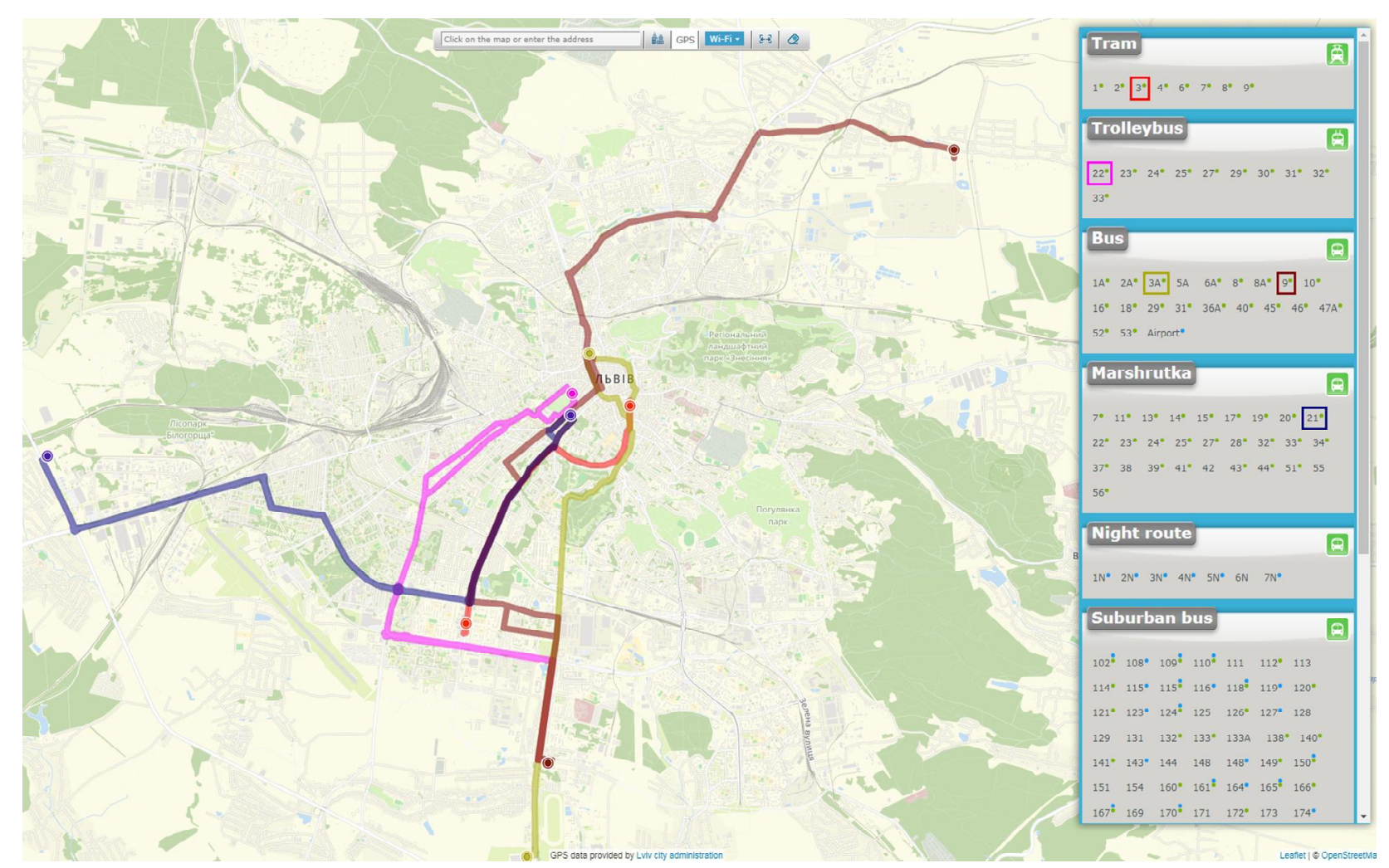

Fig. 2. Studied routes of public transport

The general characteristics of these routes are given in Table 1.

Table 1

Characteristics of routes

\begin{tabular}{|c|c|c|c|c|c|}
\hline $\begin{array}{c}\text { Route } \\
\text { number }\end{array}$ & Vehicle & Carrier company that serves & $\begin{array}{c}\text { Length in } \\
\text { straight } \\
\text { direction, } \\
\mathrm{km}\end{array}$ & $\begin{array}{c}\text { Year of } \\
\text { rolling stock } \\
\text { production }\end{array}$ & $\begin{array}{c}\text { The capacity } \\
\text { of transport, } \\
\text { persons }\end{array}$ \\
\hline $3 \mathrm{~A}$ & Electron A18501 & ATP \#1 & 8.22 & 2016 & 100 \\
\hline 9 & Ataman A093H6 & ATP \#1 & 19.12 & 2012 & 52 \\
\hline 21 & BAZ-A079 «Etalon» & ATP-14630 & 13.19 & 2002 & 40 \\
\hline 2 & Electron T19 & "Lvivelectrotrans" & 8.02 & 2014 & 106 \\
\hline 2 & Skoda 14-Tr & "Lvivelectrotrans" & 8.02 & 1999 & $80 / 106$ \\
\hline 3 & Tatra KT-4 & "Lvivelectrotrans" & 5.54 & 1997 & 141 \\
\hline 8 & Electron T5L64 & "Lvivelectrotrans" & 6.08 & 2013 & 250 \\
\hline
\end{tabular}

These route directions are quite popular among the citizens. A large number of passengers use their services every day. It is also taken into account that the way their direction passes through main streets and district roads. The average travel time on them is about 35-40 minutes.

As can be seen from the diagram (Fig. 2), all routes originate from the periphery and merge in the central part of the city, where traffic problems, frequent traffic jams, etc. are most common. They are chosen so that the duration of the trip to the city center, road conditions, and the quality of street coverage have similar properties. 
To assess passenger FS, the Stress Index of regulatory systems tension (SI) was applied, measured in arbitrary units and normally should not exceed 180 c.u. [10]. To determine it, the Polar H10 device [11] and the CardioMood mobile application [12] were used.

The main document that regulates the levels of vibration is DSN 3.3.6-039-99 "State sanitary norms of general and local vibration" [13]. According to these documents, the maximum level of total transport vibration with a frequency of $16 \mathrm{~Hz}$ and a vibration acceleration value of $0.63 \mathrm{~m} / \mathrm{s}^{2}$ in $1 / 3$ octave frequency bands is $66 \mathrm{~dB}$. Measurements were performed using the mobile application "Vibration Meter" [14].

Permissible values of the studied noise indicators, based on the author's research [15], should not exceed $60 \mathrm{~dB}$ for cars and $70 \mathrm{~dB}$ for route vehicles. Measurements of noise levels in the passenger compartment of route vehicles were carried out using the application "Soundmeter-Noisedetector" [16].

The kinetic sensations perceived by the human vestibular apparatus also play an important role in determining public transport comfort. Their evaluation can be performed by determining the force of acceleration or braking relative to the constant, which is responsible for the acceleration of free fall $\mathrm{g}$ (relative to the spatial axes X, Y, Z). Due to the influence of various factors, the comfortable deceleration during service braking should not exceed $2-2.5 \mathrm{~m} / \mathrm{s}^{2}$ or $0.2-0.25 \mathrm{~g}$ [17]. To determine the effect of kinetics on the passenger's FC, the mobile application "Accelerometer Counter" was used [18].

\section{MAIN PART}

The bus routes were the first to be analyzed, which, taking into account the peculiarities of their passage, were filled at a similar rate with a deviation of the cabin occupancy rate factor to a maximum of 0.2. The results are shown in the comparative graph of changes in the passenger's SI during the trip for different types of vehicles on the bus route (Fig. 3).

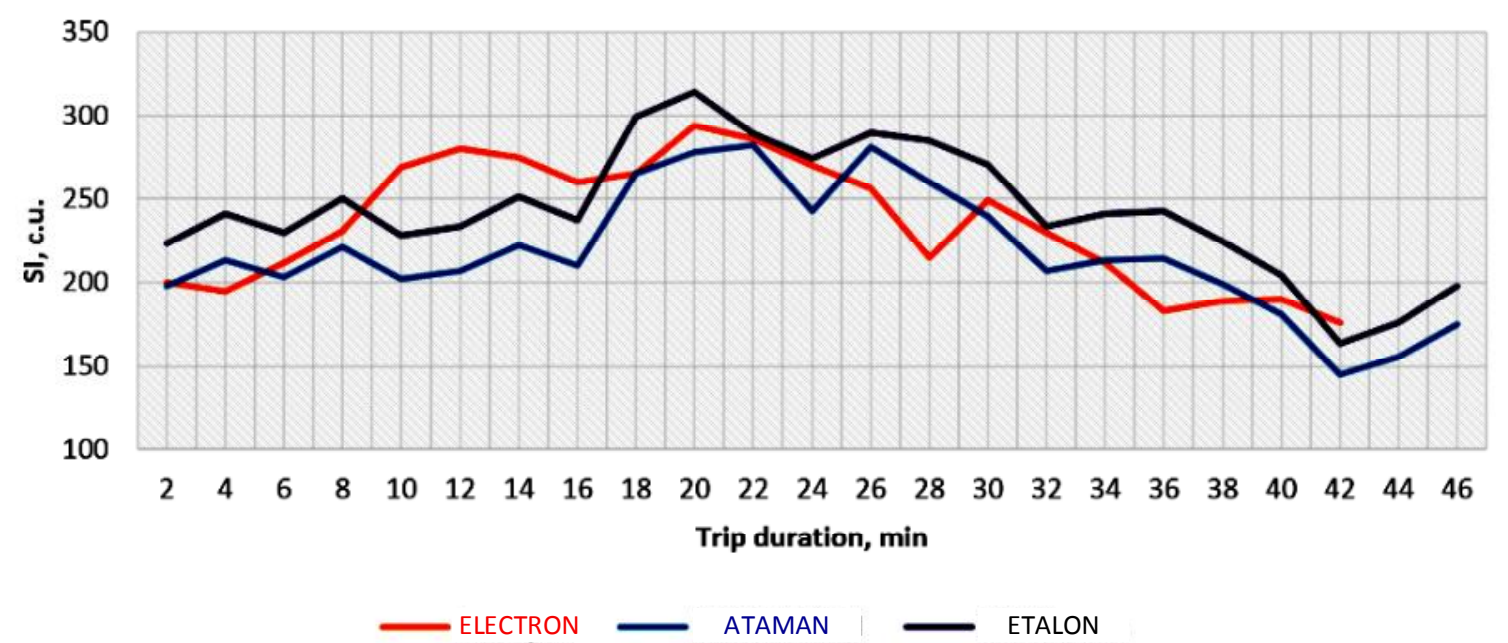

Fig. 3. Change of passenger's SI from the trip duration on bus routes

Almost the same travel conditions are on the route \#3A and \#9. Much worse conditions are on the route \#21. To some extent, the technical condition of the vehicle, the duration of the operation and the overall level of comfort, including the vehicle ergonomic features (noise, vibration, acceleration, or braking) play an important role in this case.

Electric transport is no less popular than the bus, primarily because the fare on it until recently was an order of magnitude cheaper, although, over the past year, it has leveled off. Another important reason is that for many public transport users, a tram or trolleybus ride is considered more comfortable than a minibus or bus trip.

The results of the research conducted on the trolleybus route are shown in Fig. 4. It should be noted that the occupancy rate of the cabin differed minimally on its types at similar intervals, as different types of vehicles that run on a common route are studied. 

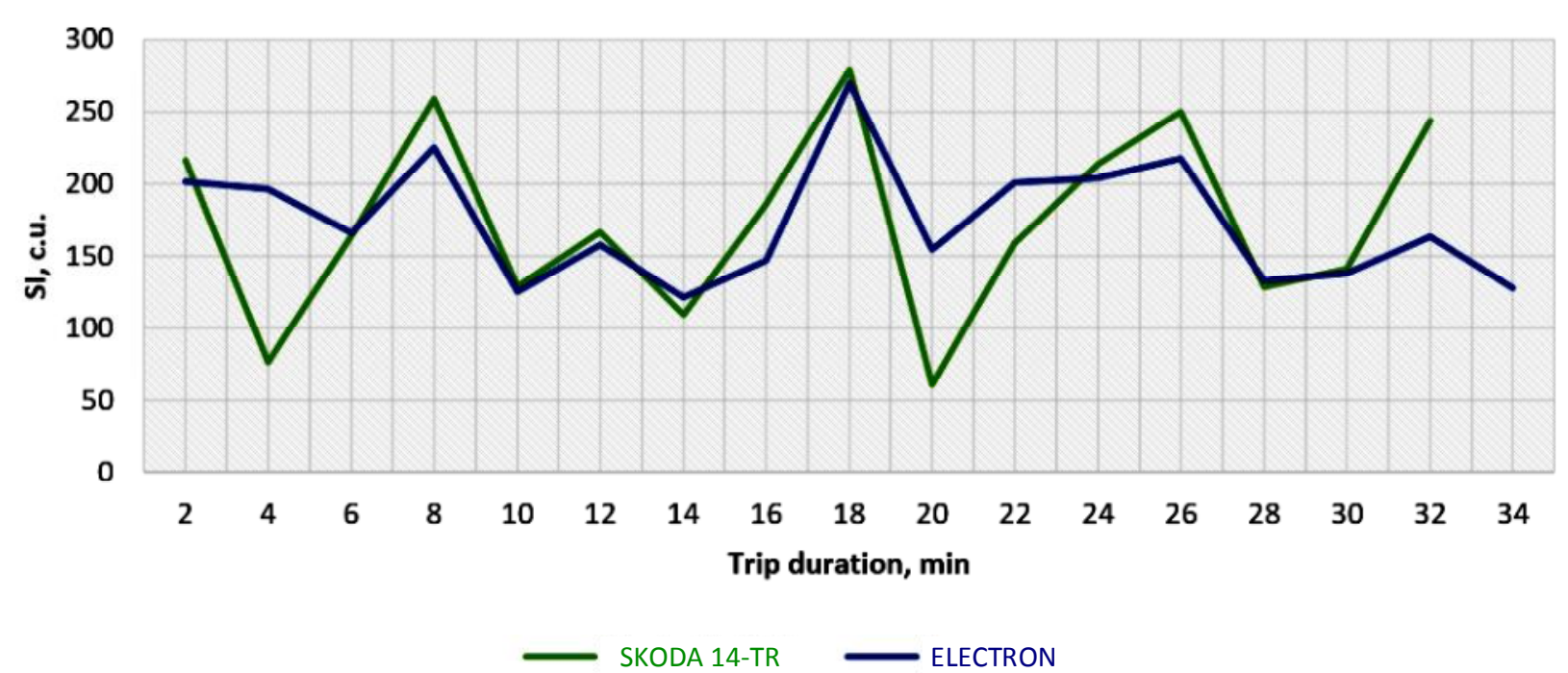

Fig. 4. Change of passenger's SI from the trip duration on trolleybus routes

The SI when using electric vehicles, in comparison with bus routes, is much lower, however sharp differences of values are observed. These differences can be seen slightly less when using the updated vehicles, which, as it turned out, play a significant role in changing the passenger's FS due to better ergonomic properties.

The study of passenger's FS change on the tram route in Lviv is of special importance, as this type of transport is the most passenger-intensive and has the best carrying capacity compared to the previous two. The research results are shown in Fig. 5.

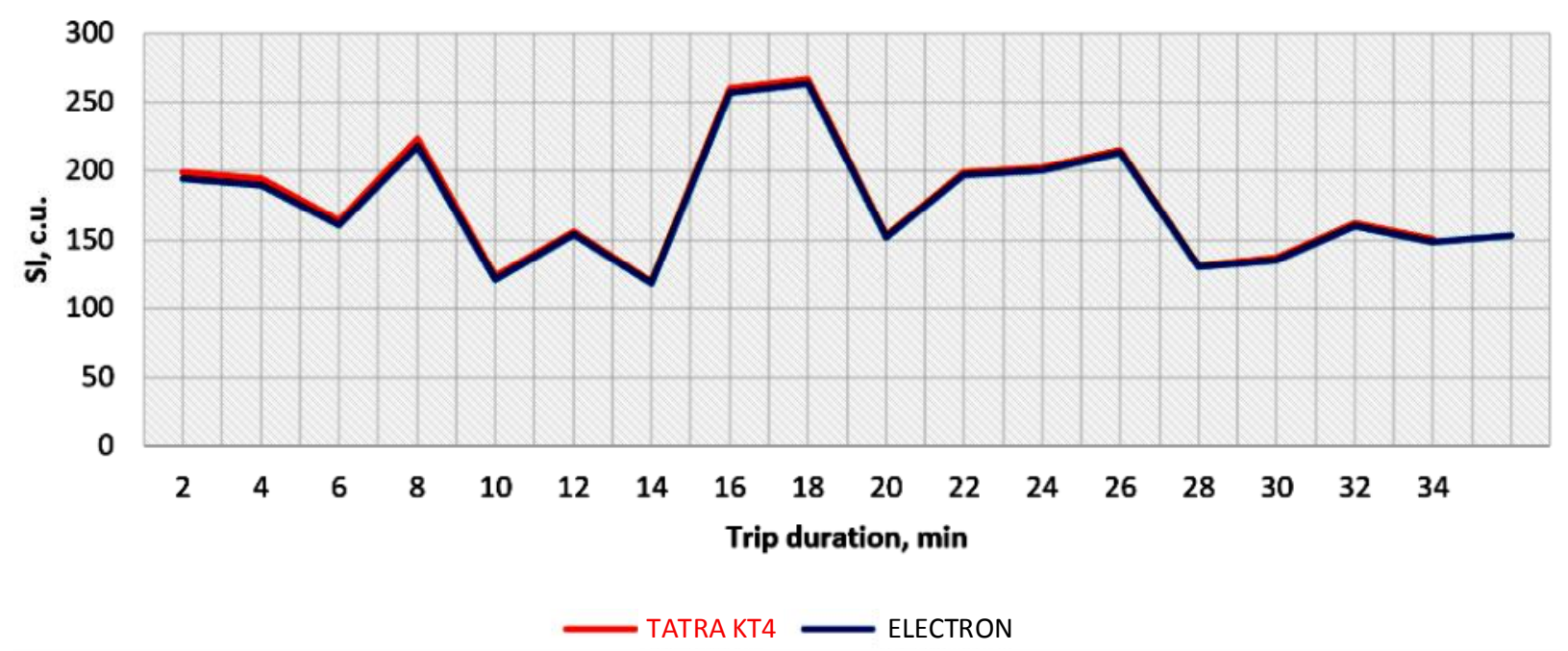

Fig. 5. Change of passenger's SI from the trip duration on tram routes

It should be noted that the Tatra KT4 tram, which was recently purchased by the city in Germany, has been used for more than twenty years, and the Electron tram, which was released in 2013, has almost the same effect on changing the passenger's FC. That is, in this case, the quality of workmanship, standards of use, and constant, timely repairs and inspections, which were carried out over a long period of operation, play a significant role in the quality of vehicle which provides better travel comfort for passengers.

A comparative analysis of ergonomic features considering all types of vehicles for their ergonomic features and the impact on passengers FS is given below:

Based on the results of the research, we can draw preliminary conclusions about the quality of different modes of transport by used vehicles. The values of the SI indicate that the most comfortable 
vehicle from the passenger's point of view is the Electron T19 trolleybus (average SI is 164 c.u.), in addition, such vehicle is the least noisy $(49 \mathrm{~dB})$. The smoothest course is observed on Electron A18501 buses (average acceleration or deceleration rate is $0.31 \mathrm{~g}$ ), and the lowest level of vibration, which is $60 \mathrm{~dB}$, is observed in trams.

Table 2

Comparative analysis of vehicle's ergonomic characteristics on the studied routes

\begin{tabular}{|c|c|c|c|c|c|c|c|c|c|}
\hline \multirow{2}{*}{ Route } & \multirow{2}{*}{ Vehicle } & \multicolumn{2}{|c|}{ SI, c.u. } & \multicolumn{2}{c|}{ Noise level, dB } & \multicolumn{2}{c|}{ Acceleration, g } & \multicolumn{2}{c|}{ Vibration, dB } \\
\cline { 3 - 12 } & & max. & av. & max. & av. & max. & av. & max. & av. \\
\hline 3A & Electron A18501 & 270 & 202 & 84 & 67 & 0.49 & 0.31 & 83 & 67 \\
\hline 9 & Ataman A093H6 & 282 & 218 & 99 & 68 & 0.67 & 0.42 & 83 & 63 \\
\hline 21 & BAZ-A079 «Etalon» & 299 & 243 & 97 & 74 & 0.81 & 0.46 & 82 & 65 \\
\hline 2 & Electron T19 & 260 & 164 & 83 & 49 & 0.48 & 0.36 & 67 & 62 \\
\hline 2 & Skoda 14-Tr & 270 & 179 & 86 & 68 & 0.51 & 0.39 & 68 & 64 \\
\hline 3 & Tatra KT-4 & 267 & 172 & 90 & 68 & 0.48 & 0.34 & 64 & 60 \\
\hline 8 & Electron T5L64 & 263 & 176 & 89 & 68 & 0.47 & 0.35 & 64 & 60 \\
\hline
\end{tabular}

Using the Statistica software, the correlation coefficients of the studied quantities were found, their values are given in Table 3 .

Table 3

Correlation coefficients of the studied quantities

\begin{tabular}{|c|c|c|c|c|c|c|}
\hline & Travel time & SI & Acceleration & Vibration & Noise level & Occupancy rate \\
\hline Travel time & 1 & 0.170507 & 0.159766 & 0.12053 & 0.293288 & 0.175826 \\
\hline SI & 0.170507 & 1 & 0.618004 & 0.671757 & 0.733469 & 0.514943 \\
\hline Acceleration & 0.159766 & 0.618004 & 1 & 0.978136 & 0.463219 & 0.379296 \\
\hline Vibration & 0.12053 & 0.671757 & 0.978136 & 1 & 0.516641 & 0.368013 \\
\hline Noise level & 0.293288 & 0.733469 & 0.463219 & 0.516641 & 1 & 0.447466 \\
\hline Fullnes & 0.175826 & 0.514943 & 0.379296 & 0.368013 & 0.447466 & 1 \\
\hline
\end{tabular}

According to Table 3, red is highlighted those values that have strong correlations with each other, respectively - black are those that interact but have a weak connection. How the SI value correlates with each of the studied elements is shown in Fig. 6.

The correlation coefficient between SI and acceleration is 0.62 , which is a significant value and indicates a strong relationship between these indicators. The diagram shows that a large number of common points account for the acceleration index between 0.4-0.6 g and at SI 180-220 c.u.

The values that are most common in the study of the correlation between SI and vibration are in the range of 62-64 dB and 180-220 c.u., the correlation coefficient for them is 0,67 .

The highest correlation coefficient is 0.73 , obtained for the values of IN and noise, which, in turn, means a strong relationship between the two samples. The most correlated values are in the range of 60-80 dB and 180-220 c.u.

It is considered that the occupancy rate of the vehicle has the greatest influence on the value of SI. However, the study proves that the occupancy rate, by itself, has the least impact on the passenger's FS. The correlation coefficient is the lowest of the considered indicators and is 0.51 . But, when other factors are interacting, it has a significant impact on the passenger's comfort. For better vision, the relationship between studied values and their impact on the passenger's FC should depict them in the form of 3D graphs (Fig. 7). 
Influence of public transport ergonomic features on passenger's functional state

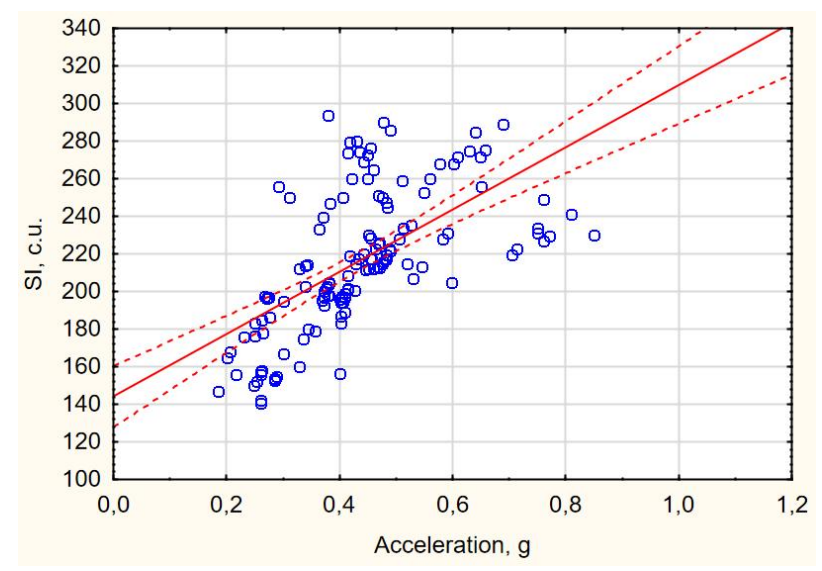

$a$

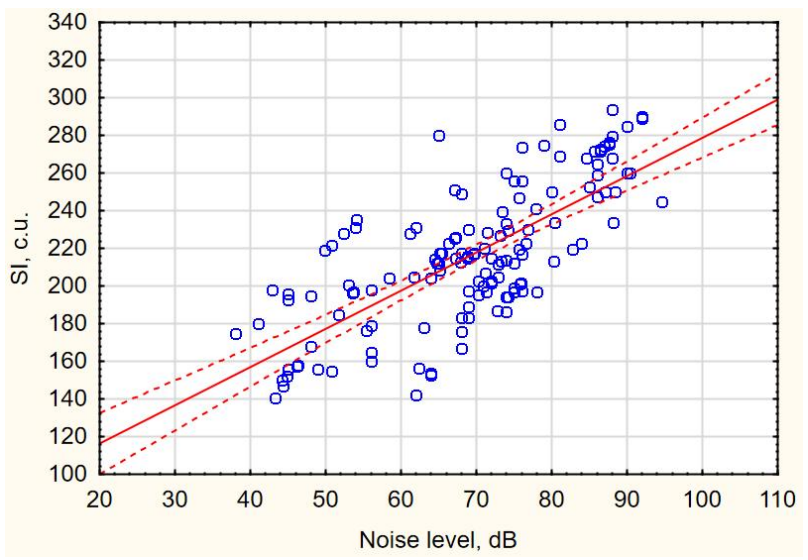

c

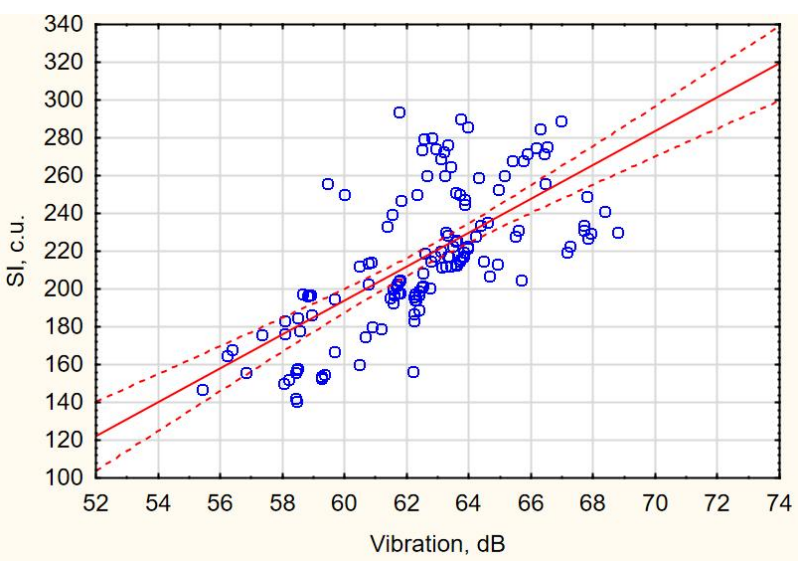

$b$

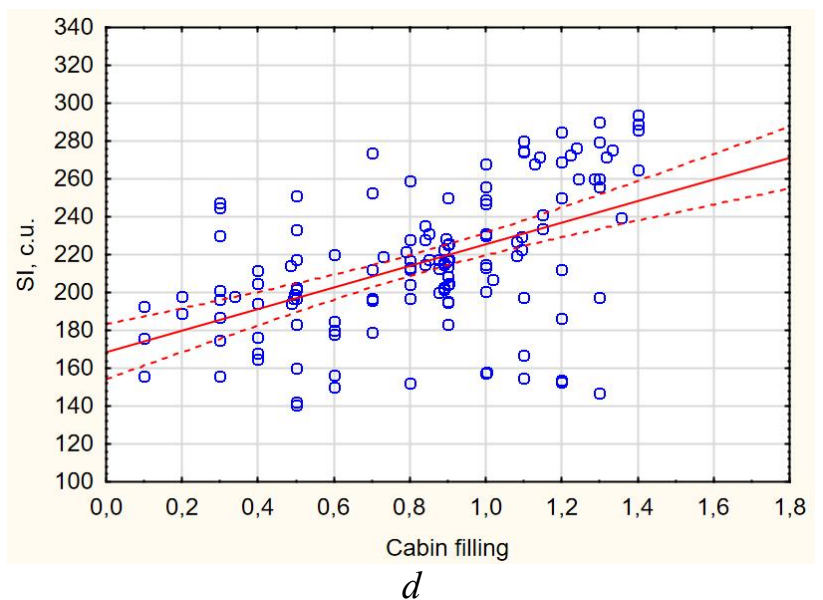

Fig. 6. Correlation diagrams of scattering SI and:

$a$-acceleration; $b$-vibration; $c$-noise level; $d$-cabin occupancy rate

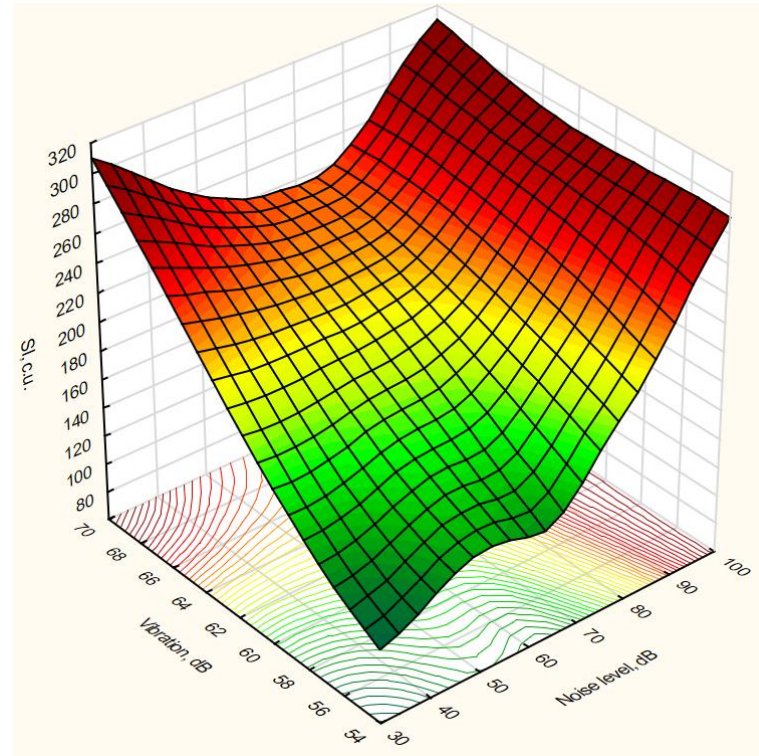

$a$

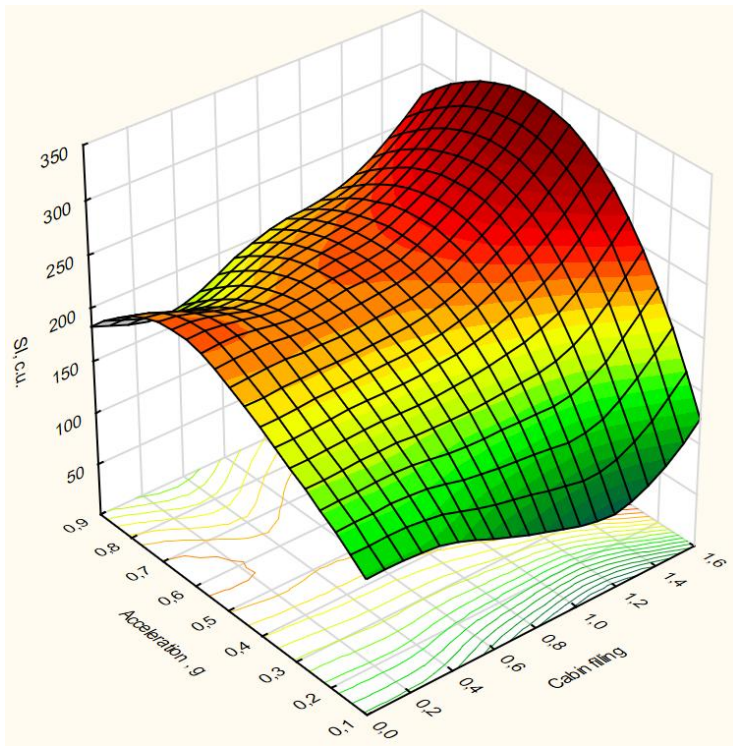

$b$

Fig. 7. 3D Graphic of SI change from:

$a$-noise level and vibration; $b$ - acceleration and cabin occupancy rate; 

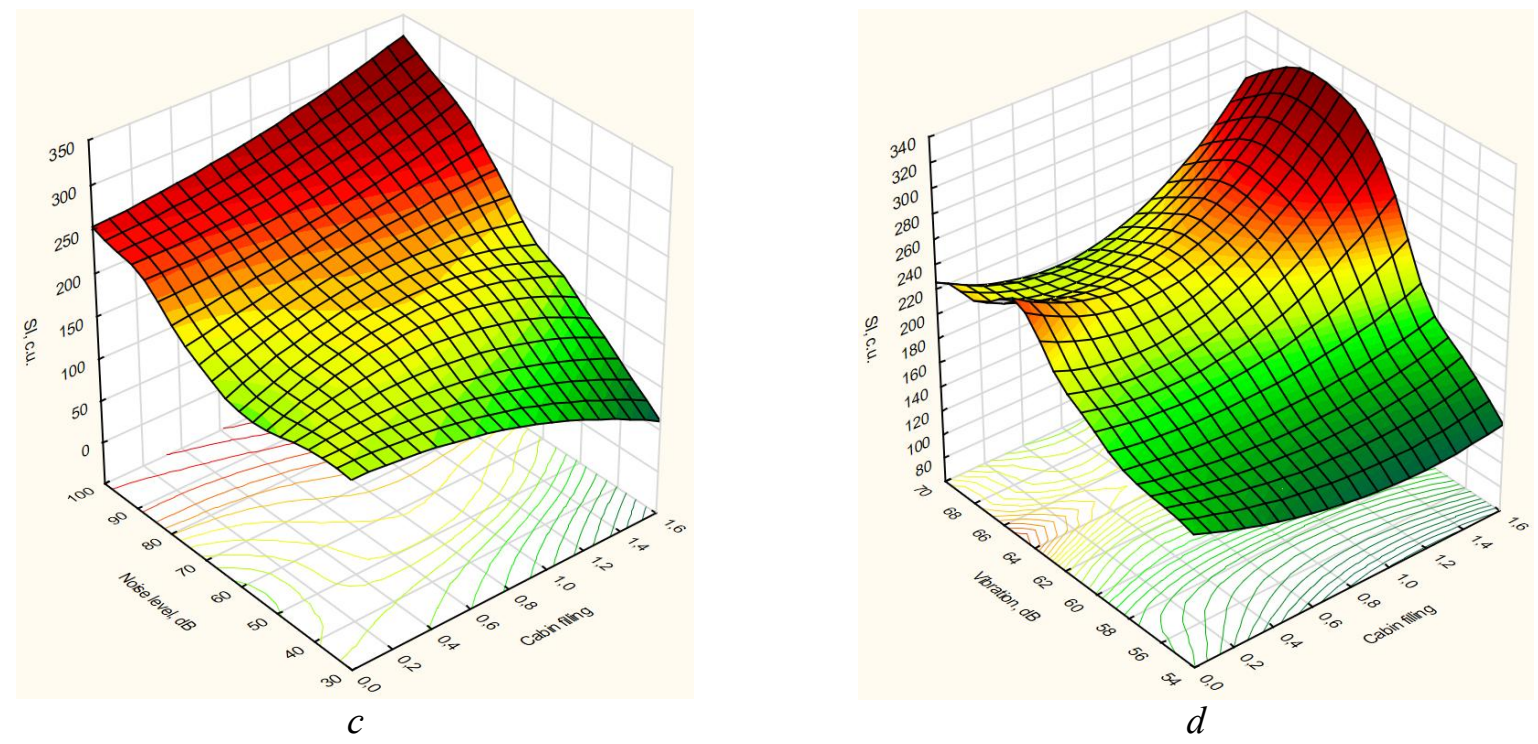

Fig. 7. (Continuation). 3D Graphic of SI change from: $c$-noise level and cabin occupancy rate; $d$-vibration and cabin occupancy rate

To ensure optimal conditions for the movement of public transport passengers, the values of vibration are in the range of 54-56 dB, noise - 30-40 dB, and SI - 80 c.u., even for the values of the cabin occupancy rate greater than 1.0. Acceleration that reaches the range of $0.5-0.8 \mathrm{~g}$ leads to a deterioration of the SI to the mark of 300 c.u., noise level in the range of 80-100 dB and occupancy rate, greater than 1.0 also has a negative effect on the value of SI -300-350 c.u.

At the maximum values of the occupancy rate, the effect of vibration in the range of 64-66 dB is felt by passengers much stronger than at an average occupancy rate of 0.6-0.8. Respectively, in the first case, the SI is 200-220 c.u., and in the second - more than 290 c.u. This sharp increase is because in addition to the strong vibration on the passenger's body is the effect of overcrowding.

According to the results of research and statistical analysis, mathematical models of passenger's FS changes depending on the indicators that characterize ergonomic features of public transport. In general, three mathematical models have been created to describe the change of SI through variables:

1. Noise level and cabin occupancy rate;

2. Vibration and cabin occupancy rate;

3. Acceleration and cabin occupancy rate.

Parameters of these models are shown in Fig. 8-10.

\begin{tabular}{|c|c|c|c|c|c|c|}
\hline \multirow[b]{2}{*}{$N=137$} & \multicolumn{6}{|c|}{$\begin{array}{l}\text { Regression Summary for Dependent Variable: IH, y.o. (Bce) } \\
R=, 76261311 \mathrm{R} ?=, 58157875 \text { Adjusted } R ?=, 57533366 \\
\mathrm{~F}(2,134)=93,126 \mathrm{p}<0,0000 \text { Std. Error of estimate: } 23,999\end{array}$} \\
\hline & $\mathbf{b}^{\star}$ & $\begin{array}{c}\text { Std.Err. } \\
\text { of } b^{\star}\end{array}$ & b & $\begin{array}{l}\text { Std.Err. } \\
\text { of } b\end{array}$ & $t(134)$ & p-value \\
\hline Intercept & & & 74,12867 & 10,91690 & 6,79027 & 0,000000 \\
\hline Noise level & 0,628989 & 0,062484 & 1,74241 & 0,17309 & 10,06636 & 0,000000 \\
\hline Cabin filling & 0,233491 & 0,062484 & 25,82654 & 6,91140 & 3,73680 & 0,000275 \\
\hline
\end{tabular}

Fig. 8. Mathematical model parameters of SI change depending on cabin occupancy rate and noise level

According to the obtained coefficients, we can create an equation to determine the value of the noise level and charge at a known parameter of SI, or find the value of SI at the specified values of noise and occupancy rate (formula (1)). After calibration of the model, the following view was obtained:

$$
S I=1.74 \cdot n l+35.83 \cdot f+200.13,
$$

where, $S I$ - Stress Index, c.u; $n l$ - noise level, $\mathrm{dB} ; f$ - occupancy rate of the cabin. 
By analogy, the second model is given:

\begin{tabular}{|c|c|c|c|c|c|c|}
\hline \multirow[b]{2}{*}{$N=137$} & \multicolumn{6}{|c|}{$\begin{array}{l}\text { Regression Summary for Dependent Variable: IH, y.o. (Bce) } \\
R=, 73086468 \mathrm{R} ?=, 53416318 \text { Adjusted } R ?=, 52721039 \\
F(2,134)=76,827 p<0,0000 \text { Std. Error of estimate: } 25,322\end{array}$} \\
\hline & $\mathbf{b}^{\star}$ & $\begin{array}{c}\text { Std.Err. } \\
\text { of } b^{*}\end{array}$ & $\mathrm{~b}$ & $\begin{array}{l}\text { Std.Err. } \\
\text { of } b\end{array}$ & $t(134)$ & $p$-value \\
\hline Intercept & & & $-277,880$ & 51,10993 & $-5,43691$ & 0,000000 \\
\hline Cabin filling & 0,309667 & 0,063411 & 34,252 & 7,01392 & 4,88348 & 0,000003 \\
\hline Vibration & 0.557795 & 0,063411 & 7,448 & 0,84672 & 8,79649 & 0,000000 \\
\hline
\end{tabular}

Fig. 9. Mathematical model parameters of change of SI change depending on cabin occupancy rate and vibration

In this case, the indicators of occupancy rate and vibration will be unknown (formula 2):

$$
S I=34.25 \cdot f+7.45 \cdot v l-277.88,
$$

where, $v l$ - vibration level, dB.

The third model, in its turn, determines the stress index due to the variables of occupancy rate and acceleration (formula 3):

\begin{tabular}{|c|c|c|c|c|c|c|}
\hline \multirow[b]{2}{*}{$N=137$} & \multicolumn{6}{|c|}{$\begin{array}{l}\text { Regression Summary for Dependent Variable: IH, y.o. (BCe) } \\
R=, 68837104 \text { R?= } 47385469 \text { Adjusted R?= } 46600177 \\
F(2,134)=60,341 p<0,0000 \text { Std. Error of estimate: } 26,912\end{array}$} \\
\hline & $\mathbf{b}^{\star}$ & $\begin{array}{l}\text { Std.Err. } \\
\text { of } b^{*}\end{array}$ & $\mathrm{~b}$ & $\begin{array}{l}\text { Std.Err. } \\
\text { of } b\end{array}$ & $t(134)$ & p-value \\
\hline Intercept & & & 128,3484 & 8,33519 & 15,39838 & 0,000000 \\
\hline Cabin filling & 0,327678 & 0,067722 & 36,2445 & 7,49074 & 4,83857 & 0,000004 \\
\hline Acceleration & 0,493717 & 0,067722 & 132,4870 & 18,17291 & 7,29036 & 0,000000 \\
\hline
\end{tabular}

Fig. 10. Mathematical model parameters of change of SI change depending on cabin occupancy rate and acceleration

$$
S I=36.24 \cdot f+635.952 \cdot a+128.35,
$$

where, $a$ - acceleration, g.

Using the obtained mathematical models (formula (1)-(3)), it is possible to find out the parameters of acceleration, vibration, and noise at the set values of cabin occupancy rate and SI, which are within the norm.

According to the threshold level of vibration, which is $66 \mathrm{~dB}$, it's believed that provided $S I=100$ c.u., $f=0.5$, the vibration level $-52 \mathrm{~dB}$ will be sufficient. That is, such trip conditions will not cause almost any discomfort.

In the situation when the maximum allowable conditions of the passenger's trip are taken $-f=0.9$ and $S I=180$ c.u., at $v l=34 \mathrm{~dB}$, there will be no additional negative impact on the comfort of the passenger's trip.

Noise and acceleration parameters are calculated similarly. The values of the noise level in the range of 68 and $40 \mathrm{~dB}$ were obtained, and the acceleration was 0.39 and $0.53 \mathrm{~g}$ respectively, at the value of $S I=100 / 180$ c.u. and $f=0.5 / 0.9$ (Table 4$)$.

Table 4

Optimal parameters of public transport cabin microclimate

\begin{tabular}{|c|c|c|}
\hline The indicator that characterizes & \multicolumn{2}{|c|}{ Trip conditions } \\
\cline { 2 - 3 } ergonomic features of the vehicle & Comfortable & Allowable \\
\hline Stress Index, c.u. & 100 & 180 \\
\hline Cabin occupancy rate & 0.5 & 0.9 \\
\hline Noise level, dB & 68 & 40 \\
\hline Vibration level, dB & 52 & 34 \\
\hline Acceleration/ Retardation, g & 0.5 & 0.4 \\
\hline
\end{tabular}


Therefore, we can conclude that the ideal model of public transport microclimate is being implemented, according to the values given in Table 4 above.

\section{CONCLUSIONS AND RESEARCH PERSPECTIVES}

The basis of this work is the study of passenger's functional state, taking into account public transport ergonomic features. For this purpose, the research was conducted on bus route vehicles of the brands "Electron", "Ataman" and BAZ "Etalon", electric vehicles - tram "Electron" and "Tatra KT4", trolleybuses - "Electron" and "Skoda 14-15 Tr". Measurements of the studied indicators, such as stress index, vibration, acceleration, cabin occupancy rate, and noise were performed in the morning from 9: 0010: 00, lunch - 13: 00-14: 00 and in the evening - 17:00-18: 00 .

According to the research, the dependences of stress index change at different values of noise level, vibration, acceleration, and cabin occupancy rate are constructed. The results of research when traveling with different vehicle types are compared. It is established that, for example, a trip by tram brand "Tatra KT4" and "Electron" (constructed in 1997 and 2013), respectively, is almost no different despite the much older age of the first.

$3 \mathrm{D}$ graphics were created to visualize the impact of certain indicators of cabin microclimate on passenger's functional state change. The maximum limit values that occurred during the research are set.

In the software environment Statistica, mathematical models of passenger's functional condition change are constructed and, based on them, the equation for the definition of a stress index with two unknowns is deduced. As a result, the most comfortable and acceptable conditions of the trip are determined, considering the levels of noise, vibration, acceleration, and occupancy rate of the cabin and the main indicator of the comfort of the passenger's trip is his stress index.

Such criteria allow bringing the indicators of qualitative transport service as close as possible to the quantitative ones, which in future studies should serve as criteria for traffic conditions on the route in terms of passenger comfort.

\section{References}

1. Gao, Y., Rasouli, S., Timmermans, H., \& Wang, Y. (2018). Trip stage satisfaction of public transport users: A reference-based model incorporating trip attributes, perceived service quality, psychological disposition and difference tolerance. Transportation Research Part A: Policy and Practice, Volume 118, 759-775. doi: 10.1016/j.tra.2018.10.029. (in English).

2. Eldeeb, G., \& Mohamed, M. (2020). Quantifying preference heterogeneity in transit service desired quality using a latent class choice model. Transportation Research Part A: Policy and Practice, Volume 139, 119-133. doi: 10.1016/j.tra.2020.07.006. (in English).

3. Deb, S., \& Ahmed, M. A. (2019). Quality assessment of city bus service based on subjective and objective service quality dimensions. Benchmarking: An International Journal. doi: 10.1108/BIJ-11-2017-0309. (in English).

4. Boykiv, M. \& Kushpeta O. (2015). Vtomlyuvanist' pasazhyriv elektrotransportu yak kryterij ocinky yakosti transportnogo obslugovuvannya [Evaluation of quality electric vehicle maintenance of passengers]. Proceedings from Vseukrayins ka naukovo-teorety'chna konferenciya "Problemy $z$ transportnymy potokamy $i$ napryamy yix rozv'yazannya" - All-Ukrainian scientific-theoretical conference "Problems with traffic flows and directions of their solution". (pp. 141-142). Lviv: Publishing House of Lviv Polytechnic National University (in Ukrainian).

5. Kovaliova K. (2017). Vtomlyuvanist' pasazhy' riv elektrotransportu yak kry'terij ocinky yakosti transportnogo obslugovuvannya [Analysis of factors influencing the comfort of transportation in the system of urban passenger transport]. Proceedings from XXIV Mizhnarodna Naukovo-Praktychna Konferentsiia Studentiv Aspirantiv Ta Molodykh Uchenykh "Aktualni Problemy Zhyttiediialnosti Suspilstva" - XXIV International scientific-practical conference of students, graduate students and young scientists "Actual problems of society". (pp. 102-103). Kremenchuk: KrNU (in Ukrainian).

6. Vovk Y. (2017). Dependence of public transport service quality indicators priority from the respondents age. Proceedings from VII International youth science forum «litteris et artibus». (pp. 275-276). Lviv: Publishing House of Lviv Polytechnic National University (in English).

7. EN, B. (2002). 13816: 2002: Transportation. Logistics and Services. Public Passenger Transport. Service Quality Definition, Targeting and Measurement. 
8. Frolov, K. V. (2005). Formation of indicators and standards of quality of city bus transportations. Candidate's thesis. Moscow: SMU (in Russian).

9. Planning and development of territories. (2019). DBN B.2.2-12:2019 from 1th October 2001. Kyiv: Minregion Ukraine (in Ukrainian).

10. Krystopchuk M. Je. (2020). Change of drivers functional condition while moving along highways of different technical categories. Transport technologies, Volume 1, number 1, 22-32. doi: 10.23939/ tt2020.01.022 (in English).

11. Polar H10 Heart rate sensor. Retrieved from https://www.polar.com/en/products/accessories/ H10_heart_rate_sensor. (in English). English).

12. Mobile apps and web dashboard for HRV analysis. Retrieved from https://www.cardiomood.com. (in

13. State sanitary norms of general and local vibration of production. (1999). DSN 3.3.6-039-99 from 1st December 1991. Kyiv: Ukrainian Ministry of Health (in Ukrainian).

14. Vibration Meter. Retrieved from https://play.google.com/store/apps/details?id=com.basicapp.gl_vibration meter (in English).

15. Petrenko O.K. (2013). Scientific and technical principles of normalization of noise and vibration levels of vehicles. Candidate's thesis. Lviv: LPNU (in Ukrainian). English).

16. Soundmeter-Noisedetector. Retrieved from https://play.google.com/store/apps/soundmeter.noisedetectormeter (in

17. Dembitskiy V. M. (2017). Improving the efficiency of energy recovery systems of wheeled vehicles with electric drive. Candidate's thesis. Lutsk: LNTU (in Ukrainian).

18. Accelerometer Counter. Retrieved from https://play.google.com/store/apps/details?id=com.keuwl. accelerometercounter (in English).

Received 05.08.2020; Accepted in revised form 07.09.2020. 